\title{
The PMC Goes on Trial
}

\author{
John Lawton \\ University of Maryland Baltimore County
}

Liu, Catherine. (2021) Virtue Hoarders: The Case against the Professional Managerial Class. Minneapolis: University of Minnesota Press.

Safe spaces, trigger warnings, cancel culture, and virtue signaling are but a few of the controversial developments that have colored the political landscape in recent years. As with all rapid social change, these developments have been accompanied by polarization and embittered polemics. Those who most fervently tug at opposite sides of this proverbial rope typically fall into one of two categories. The first consists of crusaders who broadcast their ethics and opinions to the world, and who relish opportunities to rebuke the dissenting and the disinterested. The second category is characterized by reaction and resentment. It is populated by those, typically to the right of the political spectrum, who are exasperated by what they see as vogue pseudo-intellectual nonsense.

Voices that fall outside of this dichotomy are typically deemed negligible, but a small group of writers recognize the harm and the potential to backfire inherent to many of the cultural projects championed by the PMC. This sector appears to be growing, as evidenced by the recent publication of the now infamous "Harper's Letter." Commentary from this sphere is often pragmatic, strategic, and above all, very careful. Catherine Liu is that most rare species of intellectual whose thought cannot be comfortably situated in this framework. Indeed, her work cannot be placed anywhere in the vicinity. Unlike the Harper's Letter, which consists of a brief, largely descriptive commentary about the rise of intolerant progressivism, Lui's argument is thorough, well researched, and saturated with supporting evidence.

It is these qualities that make her work difficult to ignore, generalize away, or dispense with. Unlike attacks from reactionary quarters, which are easily dismissed, Virtue Hoarders poses a considerable threat to the PMC, a class that has become too comfortable with reactive indignation and too confident in its own moral standing. Liu knows her subjects. She works among them, and her accounts are a product of both undeniable cultural trends and first hand experience from within the belly of the PMC beast. She possesses a sophisticated understanding of the contemporary political climate, and she has exposed significant moral contradictions and cultural hypocrisies, which betray the dubious nature of many of the PMC's pet projects, its ideological dogmatism, and its penchant for outrage. These qualities are conspicuously absent from most conservative critiques of the 'New Left,' a fact that leaves the PMC ill-equipped to absorb or parry substantive arguments. Consequently, Liu has drawn attention to an important reality, one that has proven deeply inconvenient for the PMC: not all critics of the PMC and the excesses of woke culture are reactionary philistines or prejudiced imbeciles. Liu's book goes a long way in demonstrating that at least one such critic can and does run intellectual circles around the average outspoken woke member of the PMC. 
Her pithy and provocative new book, Virtue Hoarders: The Case against the Professional Managerial Class $(\$ 10$, less than $\$ 4$ for a digital copy) is brave. Actually brave, not brave in the sense in which the targets of her ire tend to use the word - to extol the reproduction of safe and predictable platitudes about which there is virtual consensus in the academy and in the mainstream. Liu's bravery stems from her willingness to place those who have made a habit of ruining the reputations and careers of dissenters in her crosshairs. She knows all too well that the kickback and vindictiveness of PMC crusaders is swift, vicious, and too often successful. Liu is aware that she is pressing buttons. Indeed she declares her intention to do so with zeal in the book's opening pages, and returns to antagonistic variations of this mission statement throughout.

While her excoriation of the PMC will make for a cathartic read for kindred intellectuals and frustrated laypeople, it is guaranteed, by design, to provoke the PMC. For Liu this is not simply a tactical point. It is embedded in her personal philosophy. In response to the PMC's puritanical morality policing, she submits that "We must be heretics. We should blaspheme" (p. 61). This is not merely a stratagem to counteract the PMC's influence; it is a means of recovering some of the humanity that we have lost to a culture bent on erasing debate and offense, and enforcing contrived virtue.

Liu writes in support of three resolutions: to breathe new life into the case for socialist ideals and policies; to "isolate the PMC's ... politics of liberal refusal to adopt and support the social and political changes we desperately need;" and to "help us do the necessary work of self-criticism while providing a few tools to attack PMC positions" (p.10). While her aggressive style is easily reconciled with the first two objectives, it is less likely that her prescriptions will be acknowledged, much less deeply contemplated by constituents of the PMC. By her own analysis, the PMC "monopolizes expertise," "blocks meaningful attempts at economic redistribution," fetishizes intelligence," and "loves nothing more than moral panics to incite its members to ever more pointless forms of pseudo-politics and hypervigilance." These colorful excerpts constitute only the tip of Liu's iceberg of acerbic prose. Furthermore, Liu convincingly argues that the PMC morality police were in no small part responsible for the cultural tides that swept Donald Trump into the oval office in 2017. It is difficult to imagine readers who recognize themselves in Liu's renditions taking her advice to heart after perusing such passages. Moreover, the casual reader who purchases a copy of the book will likely be compelled by a feeling of resentment, a consequence of first-hand experience with PMC antics.

In this respect Liu's strongest qualities are destined to work against her important message. Although her insights are piercing and her case convincing, it is her aggressive tenor that will thrill or appall readers. Notwithstanding the explicitly stated objective to equip readers with the ability to "identify PMC values in ourselves .... [and] to liquidate them" (p.74), her tone remains caustic throughout. Her treatment of the PMC would benefit from an exposition of the exact quarters of the PMC in which each issue festers. Still, her readers, "members of the PMC, or at least [those who] have been educated in its institutions" (p.75), are likely to recognize the elements of the PMC where each of Liu's grievances are most heavily concentrated.

Liu's assessment of the PMC may use a hammer where a scalpel would be more effective, but perhaps the day of cautious ideological pandering has passed. Perhaps careful, generous treatment of the PMC has too often been met with stigma and moral condescension. Perhaps it will take something as formidable as Liu's hammer and scythe to get the PMC's attention, and to forge an effective alliance between an aggrieved public, marginalized socialists, and serious intellects who recognize the magnitude of the obstacle presented by PMC hypocrisy, performativity, and self-righteous indulgence. 


\section{Cite this Review}

Lawton, John. "The PMC Goes on Trial." Rhizomes: Cultural Studies in Emerging Knowledge, no. 37, 2021, doi:10.20415/rhiz/037.r01

RHIZOMES ISSN 1555-9998 $\star 230$ East Hall Bowling Green State University Bowling Green, OH 43403

Editors: Ellen Berry and Carol Siegel. Reviews editor: Craig J. Saper. Technical editor: Helen J Burgess 